BMJ Paediatrics Open

\section{Paediatric attendances of the emergency department in a major Irish tertiary referral centre before and after expansion of free GP care to children under 6: a retrospective observational study}

To cite: Korotchikova I, Al Khalaf S, Sheridan E, et al. Paediatric attendances of the emergency department in a major Irish tertiary referral centre before and after expansion of free GP care to children under 6 : a retrospective observational study. BMJ Paediatrics Open 2021;5:e000862. doi:10.1136/ bmjpo-2020-000862

- Additional material is published online only. To view please visit the journal online (http://dx.doi.org/10.1136/ bmjpo-2020-000862).

Received 28 September 2020 Revised 6 January 2021 Accepted 28 January 2021
Check for updates

(C) Author(s) (or their employer(s)) 2021. Re-use permitted under CC BY-NC. No commercial re-use. See rights and permissions. Published by BMJ

For numbered affiliations see end of article.

Correspondence to Dr Irina Korotchikova; i. korotchikova@ucc.ie

\section{ABSTRACT}

Objectives To examine the characteristics of paediatric attendances to the emergency department (ED) in Cork University Hospital (CUH) before and after the expansion of free general practitioner (GP) care to children under the age of 6 years.

Design This is a retrospective observational study that used a large administrative dataset.

Setting The study was conducted in major Irish tertiary referral centre that serves a total population of over 1.1 million. It is a public hospital, owned and managed by the health service executive.

Participants Children aged 0-15 years who attended CUH ED during the study period of 6 years (2012-2018) were included in this study $(\mathrm{n}=76831)$.

Interventions Free GP care was expanded to all children aged $0-5$ years in July 2015.

Main outcome measures Paediatric attendances to CUH ED were examined before (Time Period 1: July 2012June 2015) and after (Time Period 2: July 2015-June 2018) the expansion of free GP care to children under 6. Changes in GP referral rates and inpatient hospital admissions were investigated.

Results Paediatric presentations to CUH ED increased from 35819 during the Time Period 1 to 41012 during the Time Period 2 (14.5\%). The proportion of the CUH ED attendances through GP referrals by children under 6 increased by over $8 \%$ in the Time Period 2 (from 10148 to 14 028). Although the number of all children who attended CUH ED and were admitted to hospital increased in Time Period 2 (from 8704 to 9320); the proportion of children in the $0-5$ years group who attended the CUH ED through GP referral and were subsequently admitted to hospital, decreased by over $3 \%$. Conclusion The expansion of free GP care has upstream health service utilisation implications, such as increased attendances at ED, and should be considered and costed by policy-makers.

\section{INTRODUCTION}

There is sufficient evidence that health in childhood has strong long-term impacts on
What is known about the subject?

A growing rate of emergency department (ED) attendances, including paediatric presentations, that contribute to overcrowding of the emergency services is a global phenomenon.

- When medical care is free of charge, children and adolescents increase the number of doctor visits.

- A $25 \%$ increase in general practitioner (GP) attendances by children aged under 6 years was observed in Ireland following the expansion of free GP care to this age group.

\section{What this study adds?}

A significant sustained increase in paediatric GP referrals to the ED of a major Irish tertiary referral centre was observed following the expansion of free GP care to children under 6 years.

- Despite the increase in paediatric GP referrals to Cork University Hospital ED, the proportion of children under the age of 6 that were admitted to hospital decreased.

- The expansion of free GP care has upstream health service utilisation implications and must be considered by policy-makers.

socioeconomic status and adulthood health. ${ }^{1-4}$ Making primary care more accessible should encourage children to seek medical attention when needed, and hypothetically improve the general population health long term.

Currently, the majority of the Irish population pay out-of-pocket fees for their general practitioner (GP) visits and these payments for primary care are the highest among the European Union countries. In 2011, the Irish government made a commitment to 
introduce universal GP care which guaranteed free GP care for all. ${ }^{6}$ The roll out of free GP care for children under 6 years was the first step taken by the government towards that goal.

On 1 July 2015, all children aged under 6 years became entitled to free GP care in Ireland. The introduction of the free GP care for children aged under 6 years was aligned with the national policy as described in the future health strategic framework and aimed to ensure effective, safe and high-quality health services for young children. ${ }^{7}$

GP referral is the preferred mode of accessing hospital services for acute presentations in Ireland. However, direct access to emergency department (ED) (by selfreferral) is also available though this is discouraged by the charge of a fee of $€ 100$ if attending without a GP referral. This fee is also levied in respect of children attending ED.

It has been shown that when medical care is free of charge, children and adolescents increase the number of doctor visits by $5 \%-10 \% .^{3}$ A US-based study that estimated the average association between outpatient and inpatient care showed that expanded use of primary care, through insurance policy changes and improved access to primary care, was associated with a greater number of hospital presentations and an increase in inpatient spending. It was noted that this was particularly the case for the conditions for which the decision to admit to hospital was potentially more at the discretion of the primary care physician. Thus, increased access to primary care does not always result in savings in secondary care as is often assumed it will. ${ }^{8}$

By December 2016, the number of children under the age of 6 years who were eligible for free GP care in Ireland doubled compared with December $2014 .{ }^{9}$ At the same time, a 25\% increase in GP attendances in this age group was reported. ${ }^{10}$ There are clear indications that the Irish primary care system provided by GPs is already under pressure and may struggle to meet demand in the near future. ${ }^{10-12}$ This might have implications for upstream health services, especially EDs, which often serve as substitutes for primary care, though not designed for this type of work.

As the next phase of rolling out of universal GP care has been announced on 5 January 2020 by the Irish government, with expansion of GP care without fees to 6 and 7 year-olds this year and further phased extension to all children aged under 13, it is important that all potential implications are considered.

This study aimed to investigate the impact of free GP care to children under the age of 6 years on the characteristics of paediatric attendances at Cork University Hospital (CUH) ED.

\section{METHODS}

This research was conducted in a major Irish tertiary referral centre and university training hospital. CUH is a public hospital owned and managed by the health service executive and serves a total population over 1.1 million. ${ }^{13}$
CUH has arguably the busiest ED in Ireland with 69982 presentations in 2019. ${ }^{13}$ The paediatric ED in CUH is audio-visually separated from the adult ED and treats all unscheduled presentations including medical and trauma.

The study used the electronic data from the Integrated Patient Management System in CUH. This is an administrative dataset. All paediatric attendances (children aged 0-15 years) to CUH ED from 1 July 2012 until 30 June 2018 were identified, allowing us to examine the ED attendances 3 years prior to and 3 years after the expansion of free GP care for under 6. The data included ED attendees' age, date of arrival, ED arrival time, ED departure time, discharge destination, attendance type (new or return) and referral type. The referral type was categorised as GP referral, including out of hours GP referrals, and non-GP referrals. The triage information on reason for attendance or the treatment received is not captured reliably and therefore was not analysed; however, whether the ED attendance resulted in an inpatient admission, transfer to a different hospital or death was considered a proxy for severity of reason for attendance.

The study used the anonymised administrative data and had full approval from the clinical ethics committee of the Cork Teaching Hospitals. Patients were not involved in this study.

Free GP care was expanded to all children aged under 6 years in July 2015 . This age group ( $0-5$ years) was used as the treatment group in the analysis. As $\mathrm{CUH}$ provides care for all children aged $0-15$ years, children aged $6-15$ years were chosen as the control group.

Two time periods were analysed:

- Time Period 1: from 1 July 2012 to 30 June 2015.

- Time Period 2: from 1 July 2015 to 30 June 2018.

To better understand the overall trend in the paediatric ED attendances in CUH over the 6-year period, a number of annual ED attendances were also analysed for each study group and for single year of age (SYOA).

We conducted logistic regression analysis stratified by time periods (Time Period 1 and Time Period 2) to assess whether the expansion of free GP care to children under 6 years affected the use of ED services, with younger children ( $0-5$ years) being the exposed group compared with older children (6-15 years). The outcome of interest was a GP referral, which represented whether the ED attendance occurred following a GP referral or not. We conducted three models to investigate the relationship between children's age and year of attendance on the probability of ED attendance being a GP referral, using different interaction terms between these variables.

In the first model, we introduced an interaction term between age ( $0-5$ or $6-15$ years) and year of attendance (six categories, from July 2012 until June 2018). In the second model, we used an interaction term between year of attendance (two categories: (July 2012-June 2015) or (July 2015-June 2018)) and age in years (as categorical variable). We further explored the effect of the introduction of free GP service to children under 6 years on CUH 
ED paediatric attendances by using an interaction term between age (as continuous variable) and attendance year (from July 2012 to June 2018) (model 3). We used interaction to allow the slope of independent variables to vary based on the main exposures (year of attendance or children's age). The predictive marginal effects of the interaction terms were plotted to better visualise how much the predicted probability of being referred by a GP changes with the change in age and year of attendance. ${ }^{15}$ All models were additionally adjusted for presentation day, time of attendance and discharge destination.

We also used cubic splines to model the shape of the association between year of attendance and the outcome, using the postrcspline package. ${ }^{16}$ The day of attendance was converted into months and treated as continuous variable (from July 2012 until June 2018). Spline coefficients cannot be interpreted directly, therefore, the model was displayed graphically, showing the predicted adjusted probability of the ED attendance being a GP referral. This model was adjusted for age, presentation day, attendance time and discharge destination. We further assessed the discharge destination in children that came through a GP referral using predictive margins plot to illustrate the results. This analysis was restricted to patients with a GP referral only, with discharge destination as an outcome (admitted/transferred/deceased or discharged home). This model was adjusted for presentation day and time of attendance with an interaction term between children's age and attendance year (July 2012-June 2015 or July 2015-June 2018). Data analyses were performed using Stata V.16.1 (StataCorp) and a significance level of $\mathrm{p}<0.05$ was used.

\section{RESULTS}

Over the period of 6 years (1 July 2012-30 June 2018), CUH ED was attended by 76831 children aged $0-15$ years; $42584(53.3 \%)$ of them came through a GP referral. There was a $14.5 \%$ increase in all paediatric attendances in Time Period 2 ( $n=41012)$ compared with Time Period $1(\mathrm{n}=35819)$. The attendances were higher in the $0-5$ years group in both study periods compared with the 6-15 years group (19199 vs 16620 in the Time Period 1 and 22934 vs 18078 in the Time Period 2, respectively). Table 1 summarises all paediatric attendances to $\mathrm{CUH}$ ED during the two study periods. Figure 1 presents the number of all paediatric CUH ED attendances by SYOA before (July 2012-June 2015) and after (July 2015June 2018) the policy change regardless of the mode of referral. The number of CUH ED paediatric attendances

Table 1 Descriptive statistics of the iPMS data for children under 6 ( $0-5$ years) and over 6 (6-15 years) who attended CUH ED during the study period (1 July 2012-30 June 2018)

\begin{tabular}{|c|c|c|c|c|}
\hline & \multicolumn{2}{|l|}{ Under 6 (0-5 years) } & \multicolumn{2}{|l|}{ Over 6 (6-15 years) } \\
\hline & July 2012-June 2015 & $\begin{array}{l}\text { July 2015-June } \\
2018\end{array}$ & July 2012-June 2015 & $\begin{array}{l}\text { July 2015-June } \\
2018\end{array}$ \\
\hline Attendances, n (\%) & 19199 (53.6) & 22934 (55.9) & $16620(46.4)$ & $18078(44.1)$ \\
\hline \multicolumn{5}{|l|}{ Referral type, n (\%) } \\
\hline GP referrals & $10148(52.9)$ & $14028(61.2)$ & $8684(52.3)$ & $9724(53.8)$ \\
\hline Non-GP referrals & $9051(47.1)$ & $8906(38.8)$ & $7936(47.7)$ & 8354 (46.2) \\
\hline \multicolumn{5}{|l|}{ Type of attendance (\%) } \\
\hline New & $18413(95.9)$ & $22016(96.0)$ & $15884(95.6)$ & $17289(95.6)$ \\
\hline Return & $786(4.1)$ & $918(4.0)$ & $736(4.4)$ & $789(4.4)$ \\
\hline \multicolumn{5}{|l|}{ Triage category (\%) } \\
\hline Immediate/resuscitation & $156(0.8)$ & $179(0.8)$ & $72(0.4)$ & $72(0.4)$ \\
\hline Very urgent/emergency & $4766(24.8)$ & 7159 (31.2) & 2696 (16.2) & $3768(20.8)$ \\
\hline Urgent & $10679(55.6)$ & $11700(51.0)$ & $9166(55.2)$ & $9562(52.9)$ \\
\hline Standard/less urgent & $2798(14.6)$ & $3401(14.8)$ & $3861(23.2)$ & $4027(22.3)$ \\
\hline Not urgent & $90(0.5)$ & $275(1.2)$ & $146(0.9)$ & $402(2.2)$ \\
\hline Not triaged/return & $710(3.7)$ & $220(1.0)$ & $679(4.1)$ & $247(1.4)$ \\
\hline \multicolumn{5}{|l|}{ Discharge dest. (\%) } \\
\hline Home & $13707(71.4)$ & $17225(75.1)$ & $12491(75.2)$ & $13799(76.3)$ \\
\hline Admitted & $5031(26.2)$ & $5382(23.5)$ & $3673(22.1)$ & $3938(21.8)$ \\
\hline Deceased & $16(0.1)$ & $8(0.0)$ & $7(0.0)$ & $6(0.0)$ \\
\hline Self-discharge & $244(1.3)$ & $216(0.9)$ & $242(1.5)$ & $214(1.2)$ \\
\hline Other & $196(1.0)$ & $97(0.4)$ & $202(1.2)$ & $116(0.6)$ \\
\hline
\end{tabular}

CUH, Cork University Hospital; ED, emergency department; GP, general practitioner; iPMS, Integrated Patient Management System. 


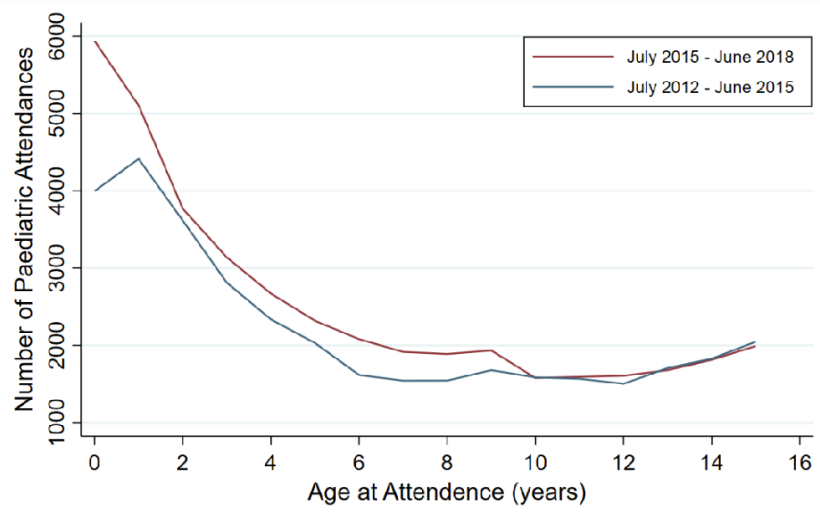

Figure 1 Number of all CUH ED paediatric attendances (0-15 years) by age: July 2012-June 2015 and July 2015June 2018. CUH, Cork University Hospital; ED, emergency department.

was highest in younger children with an increase in ED attendances observed in children under the age of 10 years after the expansion of free GP care to under 6 . There was no change in the volume of presentations in older children.

There was a clear increase in the proportions of children in both groups that were triaged as 'Very urgent/ emergency' (from $24.8 \%$ to $31.2 \%$ in the $0-5$ years group and from $16.2 \%$ to $20.8 \%$ in the $6-15$ years group) and 'Non-urgent' (from $0.5 \%$ to $1.2 \%$ in the $0-5$ years group and from $0.9 \%$ to $2.2 \%$ in the $6-15$ years group). At the same time, a decrease was observed in the proportion of children in both groups that were triaged as 'Urgent' (from $55.6 \%$ to $51 \%$ in the $0-5$ years group and from $55.2 \%$ to $52.9 \%$ in the $6-15$ years group).

There was no difference in the proportion of children who attended CUH ED as a new or return patient during the two time periods in both study groups. Similarly, no statistically significant differences were observed in the proportions of children that attended on a particular day of the week between Time Period 1 and Time Period 2 for both study groups (online supplemental table 1).

More children attended CUH ED and were discharged home in both age groups in Time Period 2 compared with Time Period 1 (17 225 (75.1\%) vs 13707 (71.4\%) in the $0-5$ years group and $13799(76.3 \%)$ vs 12491 $(75.2 \%)$ in the $6-15$ years group). There was an increase in the actual number, but a decrease in the proportion of children subsequently admitted to hospital in both age groups in Time Period 2 compared with Time Period 1 (5382 $(23.5 \%)$ vs $5031(26.2 \%)$ in the $0-5$ years group and $3938(21.8 \%)$ vs $3673(22.1 \%)$ in the $6-15$ years group).

GP referral rates were similar in both groups in Time Period 1 (52.9\% in the $0-5$ years group and $52.3 \%$ in the $6-15$ years group); however, there was a clear increase in GP referral rates in the $0-5$ years group in Time Period 2 with no similar increase in the $6-15$ years group $(61.2 \%$ in the $0-5$ year group and $53.8 \%$ in the $6-15$ years group).
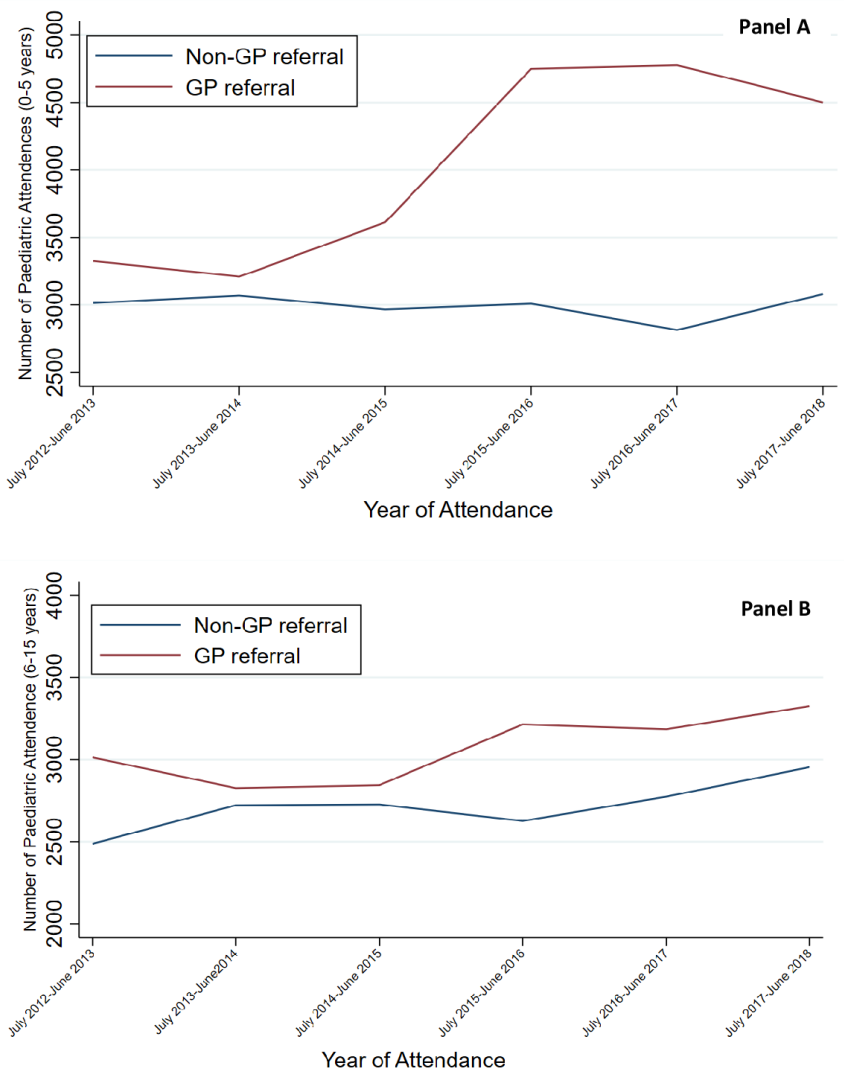

Figure 2 Number of annual CUH ED paediatric attendances through GP and non-GP referrals in children 0-5 (panel A) and 6-15 (panel B) years of age: July 2012-June 2018. CUH, Cork University Hospital; ED, emergency department; GP, general practitioner.

Figure 2 demonstrates the number of annual CUH ED attendances via a GP and non-GP referral between July 2012 and June 2018 for children aged $0-5$ years (panel A) and 6-15 years (panel B). This figure clearly shows that the number of CUH ED attendances through a GP referral in children aged $0-5$ years increased after July 2015 with no similar increase observed in the older group (6-15 years).

The results from the adjusted logistic regression model, with time as a spline explanatory variable, showed an increased probability of CUH ED attendances by children in the $0-5$ years group with a GP referral after the expansion of free GP care to under 6 in July 2015 (figure 3B). Whereas approximately the same pattern before and after the policy change was observed for ED attendances through a GP referral by children aged 6-15 years (figure 3C).

The results from the stratified analysis suggested a similar patterns of CUH ED attendances being GP referral in both younger and older children in the Time Period 1 (July 2012-June 2015), as crude and adjusted estimates did not reach a significant level (table 2). However, in the Time Period 2 (July 2015-June 2018) younger children (0-5 years) were more likely to attend CUH ED through 


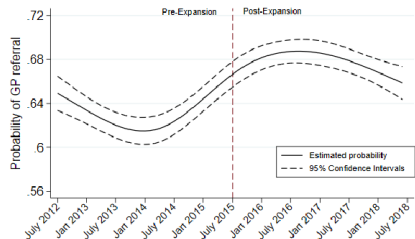

(A)

Attendance Year
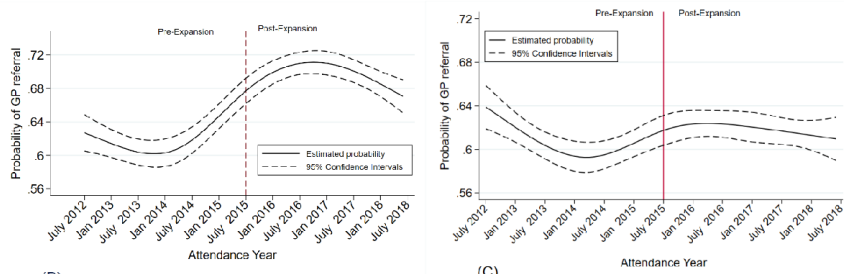

Figure 3 Spline plots of the relationship between ED attendance being a GP referral and time of attendance (time as spline explanatory variable). The model was adjusted for age, discharge destination, presentation day and attendance time. (A) Included all children (0-15 years); (B) restricted to children aged 0-5 years; $(C)$ restricted to children aged 6-15 years. ED, emergency department; GP, general practitioner.

a GP referral (adjusted OR=1.39 (95\% CI 1.33 to 1.44$)$ ) compared with older children (6-15 years) (figure 4 ).

When the analyses were extended by interacting SYOA and year of attendance, the significant increase in CUH ED attendances was seen in all ages from 0 to 5 years with no significant increase observed in children from 6 to 15 years. Results from logistic regression analysis with interaction terms between SYOA and year of attendance show that after July 2015 younger children ( $0-5$ years) were more likely to attend CUH ED through a GP referral (figures 5 and 6).

Despite the significant increase in CUH ED attendances via a GP referral in the $0-5$ years group in Time Period 2 and overall increase in the number of children in both age groups that came through a GP referral and were subsequently admitted to hospital (from 2719 to 3321 in $0-5$ years group and from 1975 to 2118 in 6-15

Table 2 Logistic regression of ED attendances being a GP referral stratified by year of attendance (July 2012-June 2015 and July 2015-June 2018)

Adjusted OR

Crude OR $(95 \% \mathbf{C l}) \quad(95 \% \mathbf{C l})^{*}$

\begin{tabular}{|c|c|c|}
\hline \multicolumn{3}{|c|}{ Year at attendance (July 2012-June 2015) } \\
\hline $0-5$ years & $1.02(0.98$ to 1.07$)$ & 1.03 (0.99 to 1.08$)$ \\
\hline $6-15$ years & Reference & Reference \\
\hline \multicolumn{3}{|c|}{ Year at attendance (July 2015-June 2018) } \\
\hline $0-5$ years & $1.35(1.30$ to 1.41$)$ & $1.39(1.33$ to 1.44$)$ \\
\hline $6-15$ years & Reference & Reference \\
\hline
\end{tabular}

*Adjusted for presentation day, attendance time and discharge destination.

ED, emergency department; GP, general practitioner.

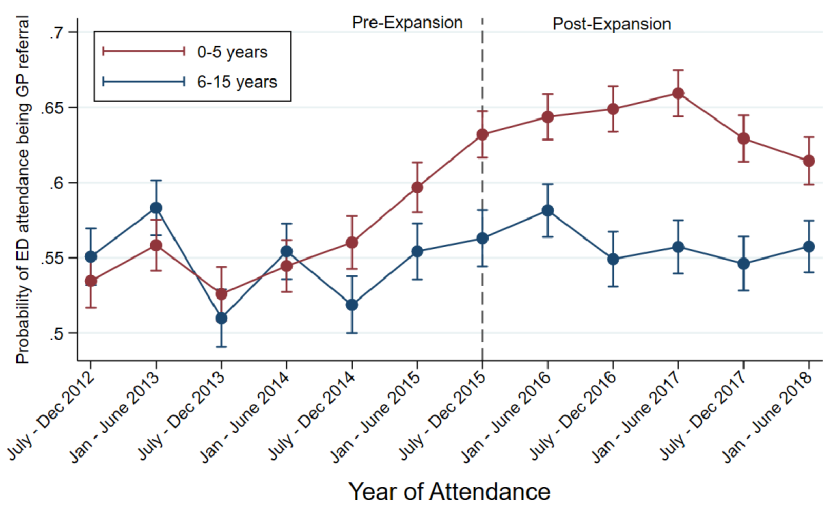

Figure 4 Predictive margins with $95 \%$ Cls of the probability of ED attendance being a GP referral with an interaction term between attendance period and age group (0-5 and 6-15 years). The model was adjusted for discharge destination, presentation day and time of attendance. ED, emergency department; GP, general practitioner.

years group), a decrease in hospital admission rates across younger ages in this study group was observed after July 2015. Figure 7 demonstrates the predictive margins with $95 \%$ CIs of the probability of ED attendance by children (0-15 years), that came through a GP referral, resulting in a hospital admission across SYOA before and after the expansion of free GP care to under 6 .

\section{DISCUSSION}

This study has shown that following the expansion of free GP care to children under 6 years in Ireland, there was an overall increase in CUH ED attendances with a significant increase in attendances via a GP referral in children under 6 years. GP referral rates remained higher in the 0-5 years group during the 3-year period post-expansion.

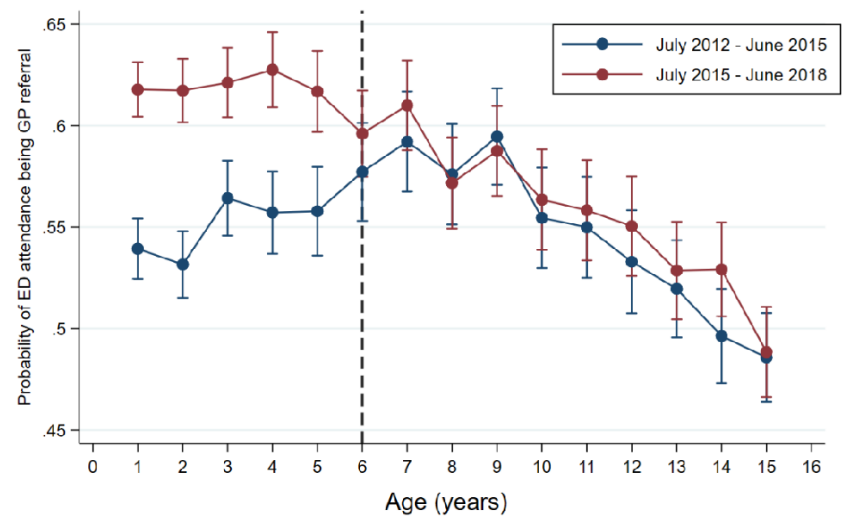

Figure 5 Predictive margins with 95\% Cls of the probability of ED attendance being through a GP referral with an interaction term between SYOA (categorical) and attendance period (July 2012-June 2015 and July 2015-June 2018). The model was adjusted for discharge destination, time of attendance and presentation date. ED, emergency department; GP, general practitioner; SYOA, single year of age. 


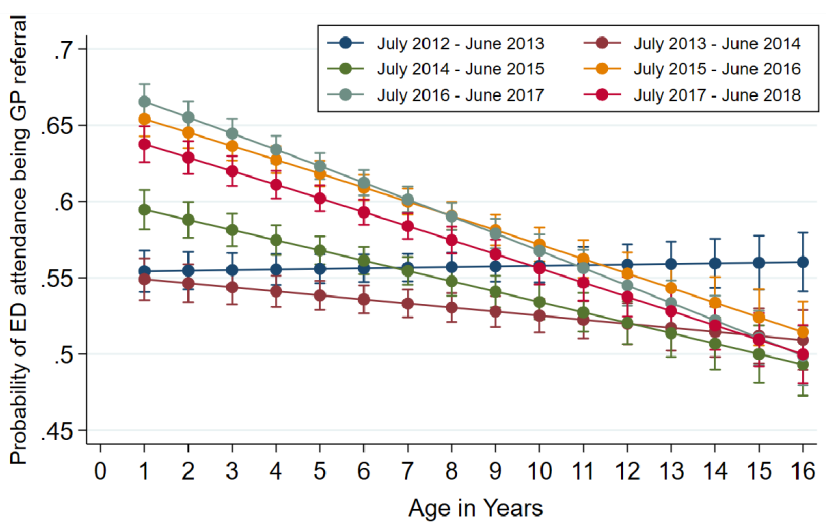

Figure 6 Predictive margins with 95\% Cls of the probability of ED attendance by children (0-15 years) being a GP referral across single year of age: July 2012-June 2018. This model included an interaction term between SYOA (continuous) and year of attendance, and was adjusted for discharge destination, presentation day and time of attendance. ED, emergency department; GP, general practitioner; SYOA, single year of age.

The number of all children who attended CUH ED and were subsequently admitted to hospital also increased (from 8704 in Time Period 1 to 9320 in Time Period 2). However, despite more than an $8 \%$ increase in the GP referral rates in the $0-5$ years group after the expansion of free GP care to under 6, the hospital admission rates in this category of children decreased by more than $3 \%$.

Previous quasi-experimental research study on the same age group in Ireland also reported an increase in the rate of GP referral to EDs in under 6 following the introduction of free GP care for under $6 .{ }^{17}$ The percentage increase reported in this study, however, was smaller than

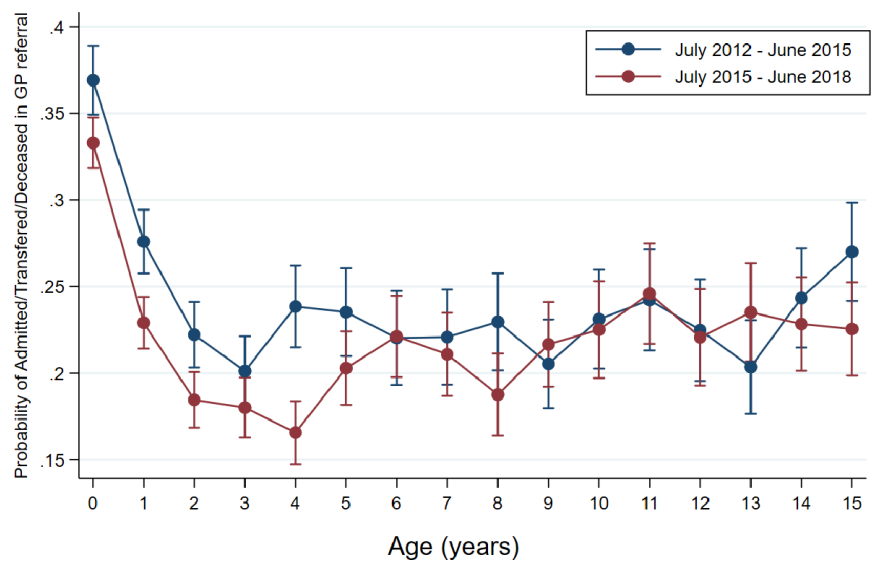

Figure 7 Predictive margins with $95 \%$ Cls of the probability of ED attendance by children ( $0-15$ years), that came through a GP referral, resulting in a hospital admission across single year of age: July 2012-June 2015 and July 2015-June 2018. This analysis was restricted to patients with a GP referral only $(n=42584)$. This model included an interaction term between children's age and attendance period (July 2012June 2015 and July 2015-June 2018), and was adjusted for presentation day and time of attendance. ED, emergency department; GP, general practitioner. in our study (2\% vs $8.3 \%$, respectively). This might be explained by the fact that the data analysed in this study were from 28 different Irish hospitals with different levels of care and were not reported for individual hospitals. Also, the observation periods in this study were much shorter than in our study and included only 6 months before and 12 months after the expansion of free GP care to under 6 , with the relevant 6 months periods compared. A much higher increase in GP referral rates in the under 6 years group following the policy change in our study can be explained by the fact that CUH is a major tertiary hospital with an extensive catchment area. Moreover, the results of our study are based on longer observation periods with overall and annual attendances compared 3 years before and 3 years after free GP care for under 6 was introduced.

Emergency department crowding is a global phenomenon with many contributing factors including inadequate access to primary care and specialists, inappropriate patient referral and the general public expectations of healthcare delivery. ${ }^{18}$ A growing rate of ED attendances, including paediatric presentations, that contribute to overcrowding of the emergency services has been reported in a number of countries. ${ }^{19-21}$ While the overuse of the paediatric ED seems a universal problem, differences in the structure of healthcare between countries have varying impacts. For example, the study from Lombardy found that only $2 \%$ of all children in the study were referred to ED by their primary care physician, whereas $89 \%$ presented on parental request with no referral. ${ }^{21}$ Different structure of the primary care in Italy where family paediatricians provide primary healthcare to all children under the age of 6 years and optionally, depending on parental preferences, up to the age of 14 years, might partially explain the low referral rate to ED by primary care physicians. Whereas the high self-referral rate could be explained by the fact that in Italy all paediatric ED attendances under the age of 14 years are free of charge regardless of the mode of presentation. ${ }^{21}$

It is obvious that the impact of free GP care expansion on paediatric ED use is multifactorial and clearly dependent on the existing healthcare system. In our study, a significant increase in GP referrals to ED for children aged $0-5$ years is important for several reasons. First, it might be reflective of increased pressure placed on already strained primary care system by increased demand and insufficient number of GPs to meet this demand. ${ }^{10}$ Second, increased paediatric ED attendances are likely to contribute to ED overcrowding. When free GP care was expanded to children under 6 years of age in Ireland, no structural reorganisation or financial support was introduced for the upstream services, including ED. Second, despite significant increases in GP referrals of children under 6 years to CUH ED, there was a significant drop in hospital admission rates in this category of patients, the largest reaching more than $7 \%$ in children aged 4-5 years. This might suggest that some of these ED presentations may have been for ambulatory 
care sensitive conditions or driven by a desire by parents and GPs to have a second opinion to resolve diagnostic uncertainty for conditions that ultimately transpired to be self-limiting.

Based on our findings several conclusions can be drawn. As the introduction of free GP care for children under 6 increases pressure on paediatric ED services, there is a strong need for investment in paediatric emergency medicine in Ireland in order to meet the increasing demands of these increasing ED presentation rates. A short stay paediatric unit, for example, has been shown to improve patient care in a cost-effective way and it could be a useful addition to the existing ED services. ${ }^{22}$ Supplying the ED with the appropriate support structures and adequate staffing must also be considered.

Better support for the primary care providers is also important. Introduction of a capitation payment system in Norway led to an increased GP referral rates to private hospitals and clinics, possibly because there was no financial incentive to undertake the procedures in the GP clinic. ${ }^{23}$ Some of the possible options, therefore would be to consider a blended model whereby GPs are remunerated for simple procedures when appropriate, for example, for managing minor injuries. A further recommendation could also include widening the GPs access to simple diagnostics, in particular X-ray. The introduction of telemedicine consultations with general paediatricians and paediatric specialists for GPs, ${ }^{24}$ as well as establishing new acute paediatric assessment services such as rapid access clinics and paediatric assessment units, ${ }^{25}{ }^{26}$ should also be explored.

\section{Strengths and limitations}

This study has evaluated the paediatric ED attendances of the major tertiary referral centre 3 years before and 3 years after the expansion of free GP care to children aged under 6 years. The observations collected over a 6 -year period allow to avoid the seasonal variation in paediatric attendances bias.

Several limitations are recognised in this study. First, due to the large dataset and inconsistent data entry we were unable to analyse the reason for CUH ED attendance by patients. This information would have been useful to better understand the spectrum of reasons for GP referrals and therefore, help to design potential solutions for the primary care support. Second, our findings might not be applicable to other Irish hospitals with smaller catchment areas and different ED structures.

\section{CONCLUSION}

Our study shows that there was a significant increase in paediatric GP referrals to CUH ED following the expansion of free GP care to children under 6 years. This increased use of the paediatric ED services might be reflective of the struggle of the primary care to meet the increased healthcare system demand and might have serious implications for the quality and safety of patients' hospital care. It is of vital importance to develop strategies to support both primary and secondary healthcare before the next phase of universal GP care is rolled out.

\section{Author affiliations}

${ }^{1}$ Medical Education Unit, School of Medicine, University College Cork, Cork, Ireland ${ }^{2}$ Department of Emergency Medicine, Cork University Hospital, Cork, Ireland ${ }^{3}$ School of Public Health, University College Cork, Cork, Munster, Ireland ${ }^{4}$ INFANT Centre, Cork University Hospital, Cork, Ireland

${ }^{5}$ Department of General Practice, School of Medicine, University College Cork, Cork, Ireland

Contributors All the authors contributed equally to the study. IK and CD were involved in designing the study and planning the data analysis. SA and IK undertook the statistical analysis. IK wrote the first draft of the manuscript. ES was involved in data collection and management. RO'B, CPB and CD contributed in writing the manuscript. $C D$ supervised the study. All authors contributed to and have approved the final manuscript.

Funding The authors have not declared a specific grant for this research from any funding agency in the public, commercial or not-for-profit sectors.

Competing interests None declared.

Patient consent for publication Not required.

Provenance and peer review Not commissioned; externally peer reviewed.

Data availability statement Data are available upon reasonable request. Data may be obtained from a third party and are not publicly available. Integrated Patient Management System (iPMS), Cork University Hospital.

Supplemental material This content has been supplied by the author(s). It has not been vetted by BMJ Publishing Group Limited (BMJ) and may not have been peer-reviewed. Any opinions or recommendations discussed are solely those of the author(s) and are not endorsed by BMJ. BMJ disclaims all liability and responsibility arising from any reliance placed on the content. Where the content includes any translated material, BMJ does not warrant the accuracy and reliability of the translations (including but not limited to local regulations, clinical guidelines, terminology, drug names and drug dosages), and is not responsible for any error and/or omissions arising from translation and adaptation or otherwise.

Open access This is an open access article distributed in accordance with the Creative Commons Attribution Non Commercial (CC BY-NC 4.0) license, which permits others to distribute, remix, adapt, build upon this work non-commercially, and license their derivative works on different terms, provided the original work is properly cited, appropriate credit is given, any changes made indicated, and the use is non-commercial. See: http://creativecommons.org/licenses/by-nc/4.0/.

\section{ORCID iDs}

Irina Korotchikova http://orcid.org/0000-0001-5908-768X

Colin P Bradley http://orcid.org/0000-0002-3595-9567

\section{REFERENCES}

1 Case A, Fertig A, Paxson C. The lasting impact of childhood health and circumstance. J Health Econ 2005;24:365-89.

2 Lundborg P, Nilsson A, Rooth D-O. Adolescent health and adult labor market outcomes. J Health Econ 2014;37:25-40.

3 Nilsson A, Paul A. Patient cost-sharing, socioeconomic status, and children's health care utilization. J Health Econ 2018;59:109-24.

4 Smith JP. The impact of childhood health on adult labor market outcomes. Rev Econ Stat 2009;91:478-89.

5 Kringos D, Boerma W, Bourgueil Y, et al. The strength of primary care in Europe: an international comparative study. Br J Gen Pract 2013;63:e742-50.

6 Connolly S, Nolan A, Walsh B. Universal GP Care in Ireland: Potential Cost Implications [GP care; healthcare expenditure; Ireland]. 2018 [updated 2018-04-06. 2018-03-27. Available: https://www.esri.ie/ publications/universal-gp-care-in-ireland-potential-cost-implications [Accessed 05 Apr 2020].

7 Department of Health. A framework for improved health and wellbeing 2013-2023, 2013. Available: https://health.gov.ie/wpontent/uploads/2014/03/HealthylrelandBrochureWA2.pdf [Accessed 30 Sep 2019].

8 Kaestner R, Lo Sasso AT. Does seeing the doctor more often keep you out of the hospital? J Health Econ 2015;39:259-72. 
9 PCRS. Statistical analysis of claims and payments, 2017. Available: https://www.hse.ie/eng/staff/pcrs/pcrs-publications/pcrs-annualreport-2016.pdf [Accessed 15 Apr 2020].

10 O'Callaghan ME, Zgaga L, O'Ciardha D, et al. Free children's visits and general practice attendance. Ann Fam Med 2018;16:246-9.

11 Collins CMG, O'Ciardha D, Ryan K. Irish College of general practitioners (ICGP). planning for the future Irish general practitioner workforce-informed by a national survey of GP trainees and recent GP graduates, 2017. Available: http://www.lenus.ie/hse/ bitstream/10147/617140/1/Planning_for_the_Future_Irish_General_ Practitioner_Workforce.pdf [Accessed $0 \overline{5}$ Apr 2020].

12 Teljeur C, Thomas S, O'Kelly FD, et al. General practitioner workforce planning: assessment of four policy directions. BMC Health Serv Res 2010;10:148.

13 CUH. HSE, 2020. Available: http://www.cuh.hse.ie/ [Accessed 05 May 2020]

14 Emergency Department Profile. Irish association for emergency medicine. Available: http://www.iaem.ie/public/irish-emergencydepartments/cork-university-hospital-cuh/ [Accessed 30 Sep 2019].

15 Orsini N, Greenland S. A procedure to Tabulate and plot results after flexible modeling of a quantitative covariate. Stata J 2011;11:1-29.

16 Buis ML. POSTRCSPLINE: Stata module containing post-estimation commands for models using a restricted cubic spline. statistical software components S456928. Boston College Department of Economics, 2008.

17 Walsh B, Nolan A, Brick A, et al. Did the expansion of free GP care impact demand for emergency department attendances? A difference-in-differences analysis. Soc Sci Med 2019;222:101-11.
18 Jayaprakash N, O'Sullivan R, Bey T, et al. Crowding and delivery of healthcare in emergency departments: the European perspective. West J Emerg Med 2009;10:233-9.

19 Cheek JA, Braitberg G, Craig S, et al. Why do children present to emergency departments? Exploring motivators and measures of presentation appropriateness for children presenting to a paediatric emergency department. J Paediatr Child Health 2017;53:451-7.

20 Centers for Disease Control and Prevention. National health interview survey, 2018. Available: https://www.cdc.gov/nchs/nhis/ SHS.htm [Accessed 10 Jul 2020].

21 Riva B, Clavenna A, Cartabia M, et al. Emergency department use by paediatric patients in Lombardy region, Italy: a population study. BMJ Paediatr Open 2018;2:e000247.

22 Browne GJ. A short stay or 23-hour ward in a general and academic children's Hospital: are they effective? Pediatr Emerg Care 2000;16:223-9.

23 Iversen T, Lurås $H$. The effect of capitation on GPs' referral decisions. Health Econ 2000;9:199-210.

24 Burke BL, Hall RW, SECTION ON TELEHEALTH CARE. Telemedicine: pediatric applications. Pediatrics 2015;136:e293-308.

25 Ogilvie D. Hospital based alternatives to acute paediatric admission: a systematic review. Arch Dis Child 2005;90:138-42.

26 Williams L, Fryer J, Andrew R, et al. Setting up a paediatric rapid access outpatient unit: views of general practice teams. BMC Fam Pract 2008;9:54. 